\title{
KEANEKARAGAMAN SPESIES DAN STATUS KONSERVASI IKAN PARI (Elamobranchii) DI PERAIRAN TARAKAN
}

\section{SPECIES DIVERSITY AND CONSERVATION STATUS OF RAY FISH (Elamobranchii) IN TARAKAN WATER}

\author{
${ }^{1}$ M. Gandri Haryono*, ${ }^{1}$ M. Firdaus, ${ }^{1}$ Sumarlin ${ }^{1}$ Syamsidar Gaffar, dan ${ }^{2}$ Mazlan \\ ${ }^{1}$ Dosen, Fakultas Perikanan dan Ilmu Kelautan, Universitas Borneo Tarakan \\ ${ }^{2}$ Mahasiswa Fakultas Perikanan dan IImu Kelautan, Universitas Borneo Tarakan \\ *email: gandriharyono@gmail.com
}

\begin{abstract}
ABSTRAK
Pulau Tarakan merupakan salah satu tempat pendaratan ikan hasil dari tangkapan nelayan di Laut Sulawesi dan merupakan salah satu lokasi kegiatan penelitian sumber daya ikan di WPPNRI 716 tahun 2019. Salah satu hasil tangkapan nelayan yang didaratkan di pulau tarakan adalah Ikan Pari. Berdasarkan dari data hasil tangkapan Ikan Pari pada tahun 2019, sebanyak 3,6 \% dari $50 \%$ hasil tangkapan ikan di Perairan Tarakan. Penelitian ini bertujuan untuk mengetahui keanekaragaman spesies serta status konservasi dari ikan pari yang didaratkan di pulau Tarakan. Pengamatan dilakukan dengan menggunakan metode survey, dengan jenis data terdiri dari data primer dan data sekunder yang diperoleh melalui wawancara, pengamatan langsung dilapangan dan studi pustaka. Hasil dari penelitian ini menunjukan bahwa ikan pari yang didapatkan sebanyak 237 individu yang tergolong kedalam 2 Famili 3 Genus dan 4 Spesies. Keanekaragaman jenis ikan pari pada daerah penelitian tergolong rendah dengan nilai indeks Shannon-Wiener sebesar $H=0.652632291$. Status konservasi ikan pari yang telah diamati selama penelitian memiliki status konservasi berdasarkan kategori IUCN Red List of Threatened Species (IUCN 2015), yaitu terdapat 2 spesies termasuk dalam kategori rentan atau vulnerable (VU), 1 spesies kedalam kategori kekurangan data atau data deficient (DD) dan 1 spesies kedalam katagori near threatened (NT).
\end{abstract}

Kata kunci: Ikan Pari, Keanekaragaman, Status Konservasi, Perairan Tarakan

\section{ABSTRACT}

Tarakan Island is one among of the fish landing sites the catch of fishermen in the Sulawesi Sea and is one of the locations for fish resource research activities in WPP-NRI 716 in 2019. One of the catches of fishermen landed on the island of Tarakan is rays. Based on data on the catch of rays in 2019 , as much as $3.6 \%$ of the $50 \%$ catch of rays in Tarakan coastal waters. This study was conducted to determine species diversity and conservation or ray status at island of Tarakan. Observations using survey methods, with the type of data consisting of primary data and secondary data obtained through interviews, direct field observations and literature studies. The results of this study showed that the rays were collected about 237 individuals from 2 Families 3 Genus and 4 Species. The diversity of rays in this study site are lowed that the Shannon-Wiener index of values $\mathrm{H}=0.652632291$. Conservation status of rays in this study has been categorized by IUCN Red List of Threatened Species (IUCN 2015) category, there are 2 species are included in the category of vulnerable (VU), 1 species is in the deficient category of data deficient (DD) and 1 species is category as near threatened (NT).

Keywords: Rays, diversity, conservation status, tarakan coastal waters 


\section{PENDAHULUAN}

Negara Indonesia merupakan Negara yang memanfaatkan penangkapan ikan pari dalam jumlah yang banyak, bahkan masuk dalam kategori yang terbesar. Akan tetapi tindakan atas kelestarian dan konservasi bagi komoditi tersebut belum cukup baik, terbilang masih sangat minim serta kekurangan data. Oleh karena itu diperlukan penelitian agar masyarakat dapat menyadari betapa pentingnya kelestarian sumber daya kelautan terutama komoditi ikan pari (kelopok Elasmobranchii). Eksploitasi telah terjadi pada beberapa wilayah perairan di negara-negara Asia. Laut Cina Selatan dan beberapa wilayah perairan di Indonesia memiliki indeks produksi relative untuk ikan-ikan Elasmobranchii di atas 10, yang mengindikasikan kondisi yang sangat tereksploitir atau dengan kata lain telah mengalami over eksploitasi (Bonfil, 2002). Produksi Elasmobranchii Indonesia pada tahun 2013 mencapai 101.991 ton (SEAFDEC, 2013).

Pulau Tarakan merupakan salah satu tempat pendaratan ikan hasil tangkapan nelayan di Laut Sulawesi dan salah satu lokasi kegiatan penelitian sumber daya ikan di WPP-NRI 716 tahun 2019. Data hasil tangkapan ikan yang menggunakan alat tangkap rawai dasar sebanyak 68 unit kapal yang beroperasi pada bulan Februari, Maret, April, September dan Desember 2019 di Laut Sulawesi adalah sebesar $9.026,5 \mathrm{~kg}$ atau dengan rata-rata 132 kg/trip/unit kapal, untuk jenis ikan pari mencapai 3,9 \% dari total hasil tangkapan 50\% (Rahmat danYahya, 2019), artinya adanya penagkapan ikan pari di Perairan Tarakan sebasar 3,9 \%. Adanya sebuah prediksi yang menyatakan bahwa, perikanan Elasmobranchii (ikan pari) di Indonesia dapat mengalami kolaps dalam beberapa kurun waktu kedepan jika tidak ada pembatasan jumlah tangkapan.
Penelitian tentang identifikasi jenis serta morfologi ikan pari sangat penting untuk dilakukan karena status konservasi ikan pari yang terbilang rentan juga tingginya konsumsi dan penggunaan dari bagian tubuh ikan pari, menyebabkan terancamnya kelangsungan hidup dari spesies ikan pari tersebut dan juga terganggunya habitat dan ekosistem yang disebabkan oleh banyaknya perburuan liar ikan pari di perairan Indonesia khususnya di perairan Tarakan. Oleh karena itu perlu dilakukan penelitian untuk mengidentifikasi jenis ikan pari yang ditangkap oleh nelayan dan keanekaragaman spesies ikan pari serta status konservasi ikan pari di Perairan Tarakan.

\section{METODOLOGI}

\section{Waktu dan Tempat Penelitian}

Metode yang digunakan dalam penelitian ini yaitu survey, yang bersifat deskriptif untuk mengetahui gambaran hasil identifikasi keanekaragaman spesies dan status konservasi dari ikan pari. Penelitian ini dilaksanakan pada bulan Juli-Agustus 2020. Adapun lokasi penelitian yang di pilih adalah lokasi para nelayan mendaratkan ikan di Pulau Tarakan, lokasi utama yakni Gudang Ikan (pengempul ikan dari nelayan) di Gunung Lingkas Ujung dan selumit pantai.

\section{Alat dan Bahan}

Adapun Alat dan bahan yang digunakan dalam pengambilan data penelitian ini meliputi: Roll meter, Timbangan, Sheet Identifikasi, Kamera, Alat tulis, Kuissioner

\section{Metode Pengambilan Data Penelitian}

Identifikasi ikan pari hasil tangkapan nelayan dilakukan dengan metode dan pendekatan pengamatan secara morfologi yaitu melihat dari struktur tubuh luar dari ikan pari itu sendiri. Pengamatan morfologi yang dilakukan, melalui bentuk mata, 
spriracle (bentuk alis mata), medio dorsal (garis lurus pada bagian atas punggung ikan pari), alar tor (bentuk bintik-bintik pada sisi kiri-kanan ujung ikan pari), dorsal and caudal fin (sirip ekor dan punggung), sirip ekor, duri ekor, sirip dada, serta bentuk leher. Untuk penyamaan bentuk morfologi menggunakan pedoman identifikasi ikan pari yang mengacu pada buku "Economically sharks and rays in Indonesia" (White et al., 2006) dan katalog IUCN 2015

Ikan pari hasil tangkapan nelayan juga diukur panjangnya untuk mengetahui gambaran umum panjang rata-rata ikan pari yang ditangkap untuk setiap jenis. Panjang ikan pari diukur dengan menggunakan roll meter, data panjang yang diukur mulai dari ujung bagian depan ikan pari hingga pangkal ekor (Disc Lenght), panjang total, serta lebar ikan pari.

Ikan pari hasil tangkapan yang telah diukur panjang dan lebarnya kemudian dihitung beratnya dengan menggunakan timbangan. Untuk mempermudah dalam pengukuran, sebelumnya ikan pari dibedakan untuk berbagai jenis ukuran berdasarkan ukuran tubuh, kemudian diambil sampling untuk masing - masing kelas ukuran yang telah dipisahkan untuk kemudian diukur berat ikannya, data ini dapat menjadikan informasi mengenai rata - rata berat ikan yang ditangkap.

Data mengenai Jenis kelamin ikan pari diambil mengingat diperlukannya data terkini menganai persentase jumlah ikan pari menurut jenis kelamin yang ditangkap di perairan Pulau Tarakan. Untuk setiap jenis ikan dan jumlah ikan yang tertangkap oleh nelayan dilihat jenis kelaminnya untuk memastikan jenis kelamin ikan pari yang ditangkap. Jenis kelamin dibedakan atas 3 kelompok jenis kelamin meliputi: kelamin jantan dewasa, jantan belum dewasa, serta jenis kelamin betina.

Rasio jenis kelamin merupakan perbandingan antara jenis kelamin jantan dan jenis kelamin betina pada ikan yang ada diperairan. Pada statistika, konsep rasio adalah proporsi populasi tertentu terhadap total populasi dengan rumus rasio kelamin. Rasio Jenis kelamin jantan ditentukan dengan menggunakan rumus sebagai berikut: \% jantan :

\section{$\sum$ jantan / $\sum$ ikan yang diamati x100\%}

Keanekaragaman jenis kelamin ikan pari dihitung dengan menggunakan indeks keanekaragaman Shannon-Wienner (Odum, 1993) dengan rumus sebagai berikut:

$$
H^{\prime}=-\Sigma P i \ln (\mathbf{P i}), \operatorname{dimana} P i=(n i / N)
$$

Keterangan:

H' :Indeks keanekaragaman Shannon-Wienner

$\mathrm{Ni} \quad$ : Jumlah individu jenis ke-i

$\mathrm{N} \quad$ :Jumlah individu seluruh

jenis

Kriteria nilai indeks keanekaragaman Shannon - Wiener (H') adalah sebagai berikut:

H' $<1 \quad$ : keanekaragaman rendah

$1<\mathrm{H}^{\prime} \leq 3 \quad$ : keanekaragaman sedang

$\mathrm{H}^{\prime}>3$ : keanekaragaman tinggi

Status konservasi ikan pari ditentukan berdasarkan acuan data IUCN 2015. Ikan pari yang ditemukan ditentukan status konservasinya dengan melihat di website IUCN. Data yang didapatkan kemudian dicatat dan dianalisis.

\section{Hasil dan Pembahasan}

\section{Identifikasi Jenis Ikan Pari Hasil Tangkapan Nelayan}

Identifikasi hasil penelitian Ikan Pari di Tarakan berdasarkan buku pedoman identifikasi Econimically Important Shark 
and Rays of Indonesia (White et., al 2006) pada lokasi penelitian di jumpai sebanyak 4 spesies Pari yang tertangkap diperairan Tarakan oleh nelayan yang didaratkan ke penampungan ikan Selumit Pantai. Hasil identifikasi ikan pari dapat dilihat pada Tabel 1.

Tabel 1. Jenis Ikan Pari Hasil Tangkapan

\begin{tabular}{ccccc}
\hline Family & Genus & Spesies & Nama Lokal & Jumlah \\
\hline \multirow{3}{*}{ Dasyatidae } & Himantura & Himantura Gerradi & Pari Jantan & 192 \\
& Himantura & Himantura Undulata & Pari Loreng & 25 \\
& Dasyatis & Neotrygon Kuhlii & Pari Minyak & 10 \\
Gymnuridae & Gymnura & Gymnura Poecilura & Pari Kupu-Kupu & 10 \\
\hline
\end{tabular}

Berdasarkan informasi yang didapatkan dari hasil wawancara dengan nelayan dan pengepul ikan di penampungan ikan Selumit Pantai Tarakan terdapat dua proses penangkapan ikan pari yaitu hasil tangkapan sampingan atau by catch dan hasil tangkapan utama. Hasil tangkapan ikan pari di dapatkan sekali mendaratkan mencapai kurang lebih $750 \mathrm{~kg}$ per satu trip tangkapan dan berdasarakan hasil wawancara kepada nelayan, penangkapan ikan dilakukan 2 kali trip dalam satu bulan dengan 7 hari melaut dan 7 hari istirahat. Hal ini dilakukan atas asumsi dari nelayan bahwa ikan pari tidak mengenal musim jadi nelayan menangkap tiap bulannya dalam satu tahun, sementara untuk tangkapan sampingan atau by catch biasanya didapatkan di perairan bulungan, ikan pari yang didapatkan biasanya jumlahnya sedikit karena biasanya ikan pari tersebut ikut tertangkap jaring oleh nelayan dari kapal penangkap ikan spesies lainnya seperti kapal penangkap cumi-cumi, tuna, tenggiri dan lainnya.

\section{Ikan Pari Himantura Gerradi}

Berdasrkan hasil pengamatan jenis Ikan pari Himantura Gerradi tidak memiliki selaput kulit di bagian bawah ekor, bentuk ekor seperti cambuk dengan corak berwarna terang dan gelap, bentuk tubuhnya seperti persegi empat, bagian atas tubuh berwarna coklat keabuan dengan memiliki bintikbintik putih yang bervariasi mulai dari hampir tidak ada sampai penuh dengan bintik, lebar badannya dapat mencapai 100 cm. Habitat Hidup Himantura Gerradi di dasar perairan kemungkinan pada dasar yang lunak, mulai dari perairan pantai hingga kedalaman $60 \mathrm{~m}$.

Himantura Gerradi merupakan hewan yang berkembang biak dengan cara vivipar dengan kecenderungan histotrofi, melahirkan 1-4 ekor anak dengan masa kandungan yang belum diketahui. Himantura Gerradi muda kerap tertangkap oleh jaring pukat setiap bulannya mengindikasikan ikan ini tidak memijah secara musiman. Crustacea, kerangkerangan dan ikan-ikan kecil merupakan jenis makanan dari Himantura Gerradi. Sampel Himantura Gerradi dapat dilihat pada Gambar 1.

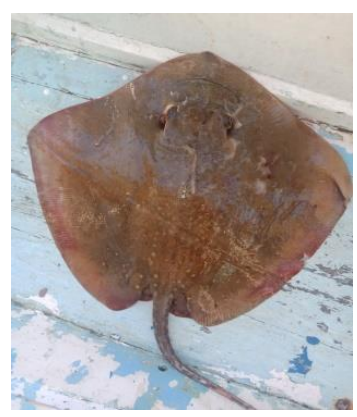

Gambar 1. Ikan Pari Jantan (Himantura gerradi) (Sumber : Dokumen Pribadi, 2020) 


\section{Ikan Pari Himantura undulata}

Berdasrkan hasil pengamatan Ikan pari Himantura undulate memiliki bentuk tubuh lonjong dengan warna kulit bagian punggung berwarna coklat dan bagian bawah berwarna putih dengan alur kembang. Habitat hidup dari ikan pari spesies Himantura undulate ini berada di dasar perairan pantai bersubstrat lunak. Himantura undulate merupakan hewan yang berkembang biak dengan cara vivipar dengan kecenderungan histotrofi. Makanannya diduga terdiri dari crustacea dan ikan-ikan kecil. Himantura undulate Tersebar luas di perairan Indo-Pasifik Barat, mulai dari India hingga Jepang dan bagian selatan Australia. White et al., (2006) menyatakan bahwa Himantura undulate sering tertangkap nelayan dengan jaring dasar, pukat dan pancing rawai. Bagian tubuh yang dimanfaatkan adalah daging, tulang dan kulitnya (bernilai niaga tinggi). Berdasarkan informasi dari nelayan spesies ini juga biasa diolah menjadi ikan asin dan dagingnya juga rasanya enak sehingga biasa diolah menjadi bahan masakan, selain itu kulitnya juga digunakan sebagai bahan kerajinan seperti dompet, tas dan sepatu. Sampel Himantura undulate dapat dilihat pada Gambar 2.

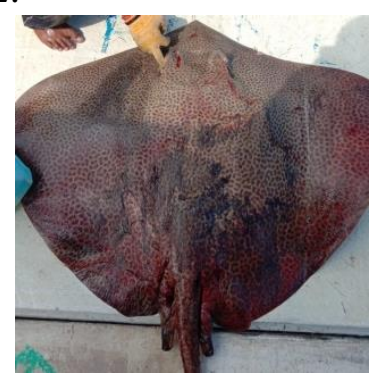

Gambar 2. Ikan Pari Loreng (Himantura undulate) (Sumber : Dokumen Pribadi, 2020)

\section{Ikan Pari Neotrygon Kuhlii}

Berdasrkan hasil pengamatan jenis Ikan pari Neotrygon Kuhlii memiliki bentuk yang lonjong dengan warna kulit bagian punggung berwarna coklat dan memiliki bintik-bintik berwarna biru. Pada bagian ekor berbentuk seperti cambuk dan terdapat alat pertahanan seperti jarum yang beracun sebagai pertahanan diri dari ancaman sekitarnya. Menurut White et al. (2006) Neotrygon Kuhlii merupakan ikan demersal di perairan dangkal dan paparan benua pada kedalaman hingga 90 m. Neotrygon Kuhlii berkembang biak dengan cara Vivipar dengan kecenderungan histotrof melahirkan 1-2 ekor anak dengan masa kandungan yang belum diketahui, waktu musim kawin tidak tetap dan makanannya terdiri dari crustacea dan ikan-ikan kecil. Berdasarkan hasil wawancara dengan nelayan bahwa Neotrygon Kuhlii ini biasa diolah menjadi ikan asin yang akan dikonsumsi untuk pribadi maupun dikirim ke luar daerah sesuai permintaan. Sebaran dan habitat dari ikan pari spesies ini terbilang luas. Allen (2000) mengatakan bahwa famili Dasyatidae mempunyai variasi habitat yang sangat luas dengan pola sebaran yang unik. Daerah sebaran ikan pari adalah perairan pantai dan kadang masuk ke daerah pasang surut. Sampel Neotrygon Kuhlii dapat dilihat pada Gambar 3.

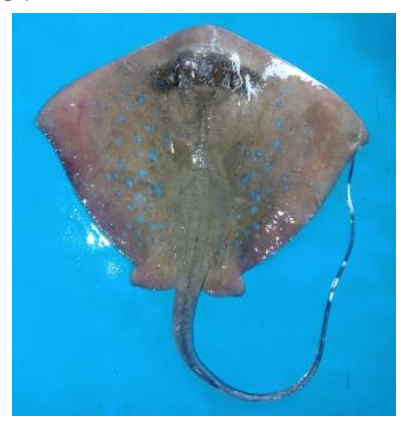

Gambar 3. Ikan Pari Minyak (Neotrygon kuhlii) (Sumber : Dokumen Pribadi, 2020) 


\section{Ikan Pari Gymnura Poecilura}

Berdasrkan hasil pengamatan jenis Ikan pari Gymnura Poecilura memiliki bentuk tubuh seperti kupu-kupu dengan bentuk tubuh lebar. Memiliki warna kecoklatan dan terdapat bintik-bintik putih pada bagian punggung. Ikan pari Gymnura Poecilura memiliki ekor lebih pendek dari pada ikan pari lainnya dan memiliki warna ekor belang pitih dan hitam. Gymnura Poecilura Termasuk kedalam hewan vivipar, dengan ketergantungan embrio pada kuning telurnya, biologinya kurang diketahui namun dilaporkan dapat berkembang biak di air tawar. Makanannya terdiri dari crustacea maupun ikan kecil dan cepalopoda. Sering tertangkap oleh jaring insang dasar. Bagian tubuh yang dapat dimanfaatkan adalah daging dan sirip (keduanya mempunyai nilai ekonomi tinggi), begitu pula kulit serta tulang rawannya.Berdasarkan wawancara dengan nelayan bahwa spesies ini sangat diminati terutama daging dan siripnya yang bernilai ekonomis tinggi, sehingga harga jual untuk spesies ini terbilang lebih mahal dibandingkan dengan ikan pari lainnya. Sampel Gymnura Poecilura dapat dilihat pada Gambar 4.

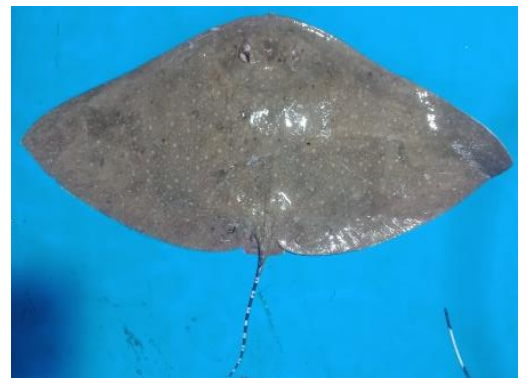

Gambar 4. Ikan Pari Kupu-Kupu (Gymnura poecilura) (Sumber : Dokumen Pribadi, 2020)

\section{Rasio Kelamin Jantan dan Betina}

Jenis kelamin jantan dan betina diketahui secara morfologi dengan mengamati adanya clasper pada jantan dan kloaka pada betina.
Rasio kelamin satu banding satu artinya komposisi ikan jantan dengan ikan betina dalam keadaan seimbang sedangkan rasio kelamin lebih dari satu yaitu dimana komposisi ikan jantan lebih banyak dari pada ikan betina, sedangkan rasio kelamin kurang dari satu artinya ikan betina lebih banyak dari pada ikan jantan (dominan). Organ reproduksi ikan pari dapat di lihat pada Gambar 5.

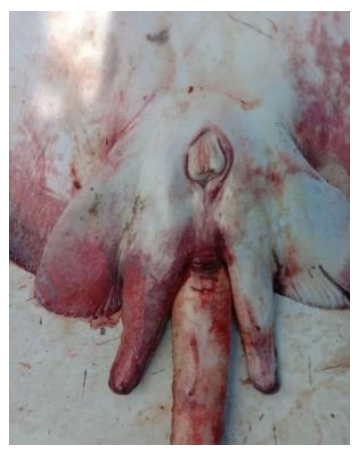

(a)

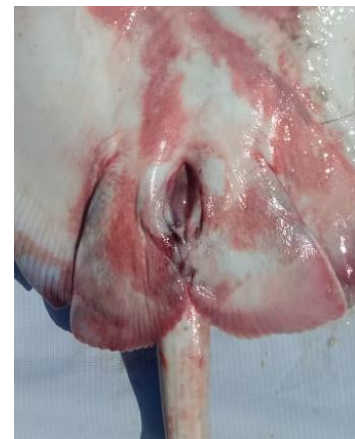

(b)
Gambar 5. Organ Reproduksi Ikan Pari (a) Jantan (b) Betina

Berdasarkan hasil pengamatan dilapangan pada penampungan ikan di Selumit Pantai Tarakan selama bulan Juli-Agustus 2020, jumlah Ikan Pari jantan lebih sedikit ditemukan dibandingkan jumlah Ikan Pari betina dimana rasio yang didapat 1:4, jumlah ikan pari jantan 58 dan betina 179 individu. Hal ini dapat dilihat pada Tabel 2.Tabel 1. Jenis ikan hasil tangkapan nelayan yang didaratkan di Pelabuhan Perikanan Pantai Tanjung Luar, Kabupaten Lombok Timur. 
Tabel 2 . Rasio jantan dan betina Ikan Pari pada penampungan Ikan Selumit Pantai Tarakan

\begin{tabular}{ccccccc}
\hline family & Genus & spesies & nama local & jumlah & jantan & betina \\
\hline \multirow{4}{*}{ Dasyatidae } & Himantura & Himantura gerradi & pari jantan & 192 & 45 & 147 \\
& & Himantura & & & & 17 \\
& Himantura & undulata & pari loreng & 25 & 8 & 17 \\
& Dasyatis & Neotrygon kuhlii & pari minyak & 10 & 2 & 8 \\
Gymnuridae & Gymnura & Gymnura poecilura & pari kupu-kupu & 10 & 3 & 7 \\
\hline & & & 237 & 58 & 179 \\
\cline { 4 - 6 }
\end{tabular}

Komposisi jantan dan betina dalam populasi merupakan faktor penting untuk kelestarian populasi. Untuk mempertahankan keberlangsungan spesies, perbandingan hewan jantan dan betina diharapkan seimbang. Rasio jantan lebih tinggi dapat mengganggu kelestarian spesies dengan

asumsi bahwa peluang jantan untuk melakukan perkawinan dan menghasilkan keturunan akan lebih rendah karena jumlah hewan betina yang terdapat dalam populasi tersebut lebih sedikit. Gangguan pada kelestarian populasi ini kemungkinan dapat lebih buruk jika

\section{Keanekaragam Ikan Pari}

Berdasarkan hasil pengamatan pada bulan Juli-Agustus, Ikan pari yang didapatkan di penampungan ikan Selumit Pantai Tarakan berjumlah 237 individu yang termasuk ke dalam 2 famili, 3 genus dan 4 spesies. Famili ikan pari yang paling banyak ditemukan adalah famili Dasyatidae sebanyak 3 spesies dan gymnuridae satu spesies. Berdasarkan hasil data pengamatan, diperoleh nilai indeks Shannon-Wiener sebesar $\mathrm{H}=0.652632291$. Indeks keanekaragaman spesies yang didapatkan, bisa dikatakan bahwa keanekaragaman spesies ikan pari yang didaratkan di penampungan ikan Selumit Pantai Tarakan tergolong dalam kategori rendah, karena besar nilai yang didapat yaitu $\mathrm{H}<1$ (Odum, 1993). Hal ini menunjukkan bahwa keberadaan ikan pari terutama spesies yang didapatkan dalam penelitian ini masih stabil di habitat aslinya, sehingga menyebabkan aktivitas penangkapan serta permintaan pasar ikan pari di penampunga ikan Selumit Pantai Tarakan tinggi.

\section{Status Konservasi Ikan Pari}

Status konservasi yang didaratkan di penampunngan ikan Selumit Pantai Tarakan, IUCN Red List of Threatened Species (IUCN 2015) tersaji pada Tabel . Ikan pari yang dijumpai sebanyak 4 spesies, dari beberapa spesies memiliki status konservasi yang berbeda-beda. Spesies $H$. gerradi dan $H$. undulata kedalam kategori rentan atau vulnerable (VU). Kategori IUCN rentan atau vulnerable (VU) diberikan untuk spesies yang terbukti memenuhi kriteria dalam IUCN, penyebabnya ialah adanya pengurangan dari ukuran populasi yang terjadi dalam waktu yang cukup lama, sehingga mengakibatkan penurunan hasil tangkapan bahkan kepunahan pada habitatnya. Hal yang menyebabkan spesiesspesies ini masuk kedalam kategori vulnerable dapat disebabkan pemanfaatan dan eksploitasi besar-besaran terutama pada daging, kulit serta sirip, sehingga jumlah dari spesies-spesies ikan pari ini di alam mengalami penurunan yang tajam terutama pada perairan Tarakan. Hal ini terlihat dari penurunan hasil tangkapan nelayan pada penampungan ikan di Selumit Pantai Tarakan. 
Spesies Neotrygon kuhlii spesies ikan pari yang masuk kedalam kategori kekurangan data atau data deficient (DD). Hal yang menyebabkan spesies Neotrygon kuhlii ini mengalami kekurangan data, bisa disebabkan biologi dan perilaku yang belum banyak diketahui, sebaran dan habitat yang luas dan tidak menentu sehingga menyebabkan sulitnya para peneliti melakukan penelitian dan pendataan, juga sifat dari kedua spesies ini yang bisa dikatakan sebagai hewan kosmopolit (spesies yang keberadaanya dapat ditemukan hampir di seluruh habitat dan ekosistem, dalam hal ini "perairan") dan nilai ekonomis yang rendah sehingga potensi penangkapan dan eksploitasi kurang diminati (Fahma,2008).

Spesies Gymnura poecilura status konservasi masuk kategori near threatened (NT). Spesies G.poecilura masih tergolong banyak pada perairan Tarakan. Jenis ikan pari yang hidupnya berkelompok dalam jumlah yang banyak sehingga pada proses reproduksinya terbilang cepat dan banyak, serta ketersedian makanan yang berlimpah, dikarenakan pada spesies $G$. poecilura memiliki sifat tidak pemilih pada makanannya. merupakan hewan yang hidupnya didalam. Dalam hal ini, jika terjadi penangkapan secara terus menurus tanpa batas eksploitasi secara berlebih tanpa adanya pengawasan atau pengendalian terhadap kegiatan perikanan dan penangkapan, maka dapat berpotensi menjadi overfishing serta eksploitasi besarbesaran yang dapat menyebabkan menurunnya jumlah populasi spesies-spesies ini di alam bebas dan untuk waktu jangka lama dapat mengalami kepunahan (White et al., 2006).

\section{KESIMPULAN DAN SARAN}

\section{Kesimpulan}

Ikan pari yang didapatkan di penampungan ikan Selumit Pantai Tarakan berjumlah 237 individu yang termasuk ke dalam 2 famili, 3 genus dan 4 spesies. Famili ikan pari yang paling banyak ditemukan adalah famili Dasyatidae sebanyak 3 spesies dan gymnuridae satu spesies. Indeks keanekaragaman spesies yang didapatkan, bisa dikatakan bahwa keanekaragaman spesies ikan pari yang didaratkan di penampungan ikan Selumit Pantai Tarakan tergolong dalam kategori rendah, karena besar nilai yang didapat yaitu $\mathrm{H}<1$ (Odum, 1993). Hal ini menunjukkan bahwa keberadaan ikan pari terutama spesies yang didapatkan dalam penelitian ini masih stabil di habitat aslinya, sehingga menyebabkan aktivitas penangkapan serta permintaan pasar ikan pari di penampunga ikan Selumit Pantai Tarakan tinggi.

Status konservasi yang didaratkan di penampunngan ikan Selumit Pantai Tarakan, IUCN Red List of Threatened Species (IUCN 2015). Ikan pari yang dijumpai sebanyak 4 spesies, dari beberapa spesies memiliki status konservasi yang berbedabeda. Spesies $H$. gerradi dan $H$. undulata kedalam kategori rentan atau vulnerable (VU). Spesies Neotrygon kuhlii spesies ikan pari yang masuk kedalam kategori kekurangan data atau data deficient (DD). Spesies Gymnura poecilura status konservasi masuk kategori rnear threatened (NT). Spesies G.poecilura masih tergolong banyak pada perairan Tarakan.

\section{Saran}

Adapun saran dari penelitian ini perlu dilakukan pengelolaan dan pengawasan terhadap eksplorasi Sumerdaya Ikan Pari diPerairan Tarakan agar lebih berkelanjutan. 


\section{DAFTAR PUSTAKA}

Allen, G. (2000). Marine Fishes of South and East Asia.A Field Guide for Anglers and Diversity. Western Australia.

Bonfil, R. 2002. Trend and patterns in world andAsian Elasmobranch fisheries. In S. L. Fowler, T. M. Reed, \& F. A. Dipper (Eds). Elasmobranch Biodiversity, Conservation, and Management. Proceeding of the International Seminar and Workshop in Sabah. July 1997. Gland, Switzerland, and Cambridge. UK. IUCN SSC Shark Specialist Group. p. $15-24$.

Bonfil, R. 1994. Overview of world Elasmobranch fisheries. Rome. FAO. 119 p.

Fahma. 2018. Keanekaragaman Spesies dan Status Konservasi Ikan Pari di Tempat Pelelangan Ikan Muara
Angke Jakarta Utara. Jurnal Biodjati, $3(1)$.

Rahmat dan Yahya. 2019. Teknik Penangkapan Ikan dengan Rawai Dasar dan Informasi Jenis Tangkapan Ikan Pari di Tarakan. BTL Vol. 17 No. 2 Desember 2019.99-103.

[SEAFDEC] South East Asian Fisheries Development Center. (2015). Fishery Statistical Bulletin of Southeast Asia 2013.

Odum, E. P. (1993). Dasar-Dasar Ekologi. Yogyakarta. Gadjah Mada University Press.

White, W. T., P. R. Last., J. D. Stevens., G. K. Yearsley. F and Dharmadi. 2006. [Buku]. Economically Important Shark and Rays of Indonesia. Penerbit: Australian Center for Internaional Agricultural Research, Australia. 